\title{
A Single Nucleotide Polymorphism in 3' Untranslated Region of Epithelial Growth Factor Receptor Confers Risk for Pulmonary Hypertension in Chronic Obstructive Pulmonary Disease
}

\author{
Sijing Zhou ${ }^{a, b}$ Min Lic Daxiong Zeng ${ }^{d}$ Xuan Xue Liming Fei ${ }^{b}$ Qingqing Zhu ${ }^{b}$ \\ Yan Zhang ${ }^{b}$ Ran Wang ${ }^{b}$ \\ ${ }^{a}$ Hefei Prevention and Treatment Center for Occupational Diseases, Hefei, ${ }^{b}$ Department of Respiratory \\ Medicine, the First Affiliated Hospital of Anhui Medical University, Hefei, 'Department of Oncology, \\ the First Affiliated Hospital of Anhui Medical University, Hefei, dDepartment of Respiratory Medicine, \\ the First Affiliated Hospital of Soochow, University, Suzhou, China; 'Division of Pulmonary/Critical Care \\ Medicine, Cedars Sinai Medical Center, Los Angeles, CA, USA
}

\section{Key Words}

$\mathrm{MiR}-214 \cdot \mathrm{COPD} \cdot \mathrm{PH} \cdot \mathrm{EGFR} \cdot \mathrm{SNP}$

\begin{abstract}
Objective: Polymorphisms located at microRNA (miRNA) binding sites may interfere with the miRNA/mRNA interaction. The objective of this study was to identify the association between a single nucleotide polymorphism $(774 \mathrm{~T}>\mathrm{C})$ in $3^{\prime}$-untranslated region ( $3^{\prime}$-UTR) of Epithelial Growth Factor Receptor (EGFR) and development of pulmonary hypertension (PH) in chronic obstructive pulmonary disease (COPD) as well as to explore the molecular mechanism. Methods and Results: In this study, we validated EGFR as a target of miR-214 in pulmonary artery smooth muscle cell (PASMC), which was further confirmed by the observation that exogenous overexpression of miR-214 significantly downregulated the expression of EGFR in the PASMCs genotyped as TT or TC, but not in CC group. Meanwhile, we found COPD patients with CC genotype had significantly higher risk for $\mathrm{PH}(\mathrm{OR}=1.965, \mathrm{p}=0.0095)$, compared with TT and TC genotypes,. Additionally, the PASMCs were isolated from 72 COPD patients, with which miR-214 and EGFR expression levels were determined, and we found that miR-214 level was comparable between each genotype group, the concentration of EGFR in CC genotype group was significantly higher than in TT or TC genotype group. Conclusion: Our study confirmed that EGFR 3'UTR 774 T>C polymorphism interfered with miRNA/mRNA interaction, and showed that the minor allele was associated with an elevated risk for development of $\mathrm{PH}$ in COPD.
\end{abstract}

Copyright @ 2015 S. Karger AG, Basel

S. Zhou and M. Li contributed equally to this work.

Ran Wang Ph.D

KARGER 125
Department of Respiratory Medicine

The First affiliated Hospital of Anhui Medical University, Hefei 230022 (P. R. China)

Tel. +86-551-62922913, Fax +86-551-62922913, E-Mail ranwang2005@163.com 


\section{Cellular Physiology Cell Physiol Biochem 2015;36:166-178 \\ \begin{tabular}{l|l|l} 
DOI: 10.1159/000374061 & (C) 2015 S. Karger AG, Basel
\end{tabular} \\ and Biochemistry Published online: April 30, $2015 \quad$ www.karger.com/cpb \\ Zhou et al.: SNP in EGFR 3'UTR Confers Risk for PH in COPD}

\section{Introduction}

Chronic obstructive pulmonary disease (COPD) is one of the leading causes of morbidity and mortality worldwide [1]. Pulmonary hypertension (PH) and right heart failure may develop in the disease course of COPD [2]. PH may cause increase in right ventricle load as well as pulmonary vascular resistance, which is a major cause of early death in COPD. The molecular mechanism underlying the pathogenesis of $\mathrm{PH}$ involves dysregulation of several biomedical signaling pathways in various cells types in lung, and aberrantly enhanced proliferation of pulmonary artery smooth muscle cells (PASMCs) at early stages of disease lead to structural changes and remodeling in pulmonary vascular bed [3]. As a complication of COPD, PH development rate and severity show a great diversity in the patient population. Therefore, identification of a genetic susceptibility to PH in COPD patients would be of important significance for a better understanding of the pathogenesis as well as developing new therapeutic target of the disease.

Epidermal growth factor receptor (EGFR) is a 170 amino acids tyrosine kinase transmembrane receptor widely expressed on the cell surface, and it has been reported to be involved in the control of some important processes of cell proliferation by modulating cell mortality and apoptosis $[4,5]$. EGFR-activating signaling pathways upregulate a wide spectrum of transcription factors by binding with EGFR ligands [6]. The over-expression of EGFR has been described in a range of malignancies, and it has been shown to be significantly associated with disease progression, resistance to chemotherapy and radiotherapy, and poor prognosis [7-9]. The dysregulation of EGFR has also been proposed to be responsible for the abnormal proliferation of PASMCs and development of pulmonary artery remodeling, and the treatment with its inhibitor could significant restore the induced vascular remodeling in rat $[10,11]$. Meanwhile, the expression level of EGFR was believed to be subject to the regulation by various factors including microRNA [12].

MicroRNAs (miRNAs) are a class of small noncoding RNA molecules that regulate gene expression by binding the "seed sequence" in 3'UTR of their target mRNAs [13]. To date, it has been estimated that more than one-third of mRNAs of human genes are regulated by human miRNAs [14]. Accumulative evidence demonstrates that miRNAs are critical for regulating the expression of oncogenes or tumor suppressor genes, which will result in tumorigenesis $[15,16]$ as well as other medical disorders $[17,18]$. Saunders et al. proposed that a single nucleotide change in the "seed sequence" of a target site may affect miRNA binding to target sites in the 3'UTR of human genes [19]. To date, significant association has been identified between the miRNA target site polymorphisms and human diseases [20-24]. Recently, Chu et al. reported one single nucleotide polymorphism (SNP, $774 \mathrm{~T}>\mathrm{C}$, rs884225) in $3^{\prime} \mathrm{UTR}$ of EGFR substantially compromised its binding with miR-214, and contributed to susceptibility to bladder cancer in a Chinese population [12].

Considering the significant contribution of EGFR dysregulation to the abnormal proliferation of PASMCs and the development of $\mathrm{PH}$, the regulatory role of miR-214 in the control of EGFR expression, as well as the evidence that rs884225 polymorphism in the 3'UTR of EGFR compromised its binding to miR-214, we hypothesized that miR-214 targets EGFR by binding to the seed sequence within a microRNA recognition element in the 3'UTR of the gene, and the EGFR 3'UTR polymorphism confers a genetic susceptibility to $\mathrm{PH}$ in COPD patients. To test this hypothesis, we performed luciferase assay to evaluate the effect of rs884225 on the interaction between EGFR 3'UTR and miR-214, determined the expression patterns of miR-214 and EGFR in the lung tissues harvested from COPD patients with and without $\mathrm{PH}$, and carried out a hospital-based case-control study to investigate the association between the rs884225 polymorphism and presence of PH in COPD patient population. Our data showed that EGFR $3^{\prime}$ UTR $774 \mathrm{~T}>\mathrm{C}$ polymorphism (rs884225) could predict the susceptibility to PH in COPD in our ongoing case-control study. 


\section{Cellular Physiology Cell Physiol Biochem 2015;36:166-178 \begin{tabular}{l|l|l}
\hline DOI: 10.1159/000374061 & (C) 2015 S. Karger AG, Basel
\end{tabular} and Biochemistry Published online: April 30, $2015 \quad$ www.karger.com/cpb \\ Zhou et al.: SNP in EGFR 3'UTR Confers Risk for PH in COPD}

\section{Materials and Methods}

\section{Study population}

A total of 328 patients with diagnosis of COPD, including 110 with PH and 218 without PH, were recruited in this study. The included COPD patients were recruited from the First Affiliated Hospital of Anhui medical University, Hefei Third Clinical College of Anhui Medical University, and the First Affiliated Hospital of Soochow University. To evaluate the effect of smoking, we conducted pack-years calculation to indicate the cumulative smoking dose [pack-years $=$ (cigarettes per day $/ 20) \times$ years smokes]. Among the recruited participants, resected specimens were available in 72 patients, who have received surgery for lung tumor resection except for 8 of the subjects with COPD undergoing volume reduction surgery. Institutional review board of Anhui Medical University approved the research protocol. After signed informed consent was obtained from all individuals, each subject donated $5 \mathrm{ml}$ blood used for genomic DNA extraction.

\section{Genotyping}

Genomic DNA was extracted from white blood cells using DNA extraction kit (Huashun, Shanghai, China). Genotyping was performed using the TaqMan (Cat. \# 4351379, Applied Biosystems, Foster City, USA) method. Probes and primers for real-time PCR were designed using the Primer Express $®$ Software v.3.0 (Applied Biosystems, Foster City, USA). Probes, specific for each allele of rs884225, were labeled with fluorescin dye at the 5' end, and contained a minor groove binder (MGB) and a nonfluorescent quencher (NFQ) at the 3' end. PCR was carried out in a 7900 Fast Real-Time PCR System (Applied Biosystems, Foster City, USA) using a 96-well. The following amplification protocol was used: $95^{\circ} \mathrm{C}$ for $10 \mathrm{~min}$, followed by 40 cycles of denaturation at $95^{\circ} \mathrm{C}$ for $15 \mathrm{~s}$, and annealing/extension at $62^{\circ} \mathrm{C}$ for $1 \mathrm{~min}$. Controls were included in each plate to ensure accuracy of the genotyping.

\section{RNA isolation and real-time PCR}

Total RNA was isolated from PASMCs obtained from the COPD patients of different genotypes using RNA isolation kit (Invitrogen, Carlsbad, CA) and then converted to complementary DNA (cDNA) using an oligo(dT)15 primer and Superscript II (Invitrogen, Carlsbad, CA). TaqMan gene expression assays were carried out using ABI 7900 to quantify relative miR-214 and EGFR mRNA expression in these samples. U6 was chosen as the internal control. All reactions were run in triplicate to reduce confounding variance.

\section{Cell culture}

Segments of pulmonary artery $(50-500 \mathrm{~m}$ external diameter) were incubated in Hanks' solution containing collagenase $(1.5 \mathrm{mg} / \mathrm{mL})$ for 20 minutes. After incubation, a thin layer of adventitia was carefully stripped off with a fineforcep, and the endothelium was removed by gentle scratching of the intimal surface with a surgical blade. The remaining smooth muscle was then digested with collagenase $(2.0 \mathrm{mg} / \mathrm{mL})$ and elastase $(0.5 \mathrm{mg} / \mathrm{mL})$ for $35-45$ minutes at $37^{\circ} \mathrm{C}$. Cells were cultured in Dulbecco's modified Eagle's Medium (DMEM) (Life Technologies Inc., USA) containing 10\% fetal bovine serum, penicillin $(100 \mathrm{U} / \mathrm{mL}$ ), and streptomycin $(100 \mathrm{mg} / \mathrm{mL})$ and cultured in a humidified incubator at $37^{\circ} \mathrm{C}$. The cells were passaged by trypsinization with $0.05 \%$ trypsin-EDTA and used for experiments at passages 3-8.

\section{Oligo transfection}

miR-214 mimics (5'- ACA GCA GGC ACA GAC AGG CAG U-3') or inhibitors (5'- ACU GCC UGU CUG UGC CUG CUG U-3') and anti-EGFR siRNA (5'-CTT CTT AAA GAC CAT CCA GG-3', designed to target EGFR mRNA exon2) were all purchased from Ambion (Austin, TX, USA). PASMC transfection was performed with lipofectamin 2000 (Invitrogen, Carlsbad, CA, USA).

Apoptosis assays

Programmed cell death rates were assessed with a commercially available apoptosis assay kit (Becton Dickinson (BD), Franklin Lakes, N)). $1 \times 10^{5}$ cells were harvested and stained with $10 \mu \mathrm{l}$ FITC Annexin V and $10 \mu \mathrm{l}$ propidium iodide. FACS sorting was performed within $1 \mathrm{~h}$ using a BD FACS Caliber (Becton Dickinson (BD), Franklin Lakes, NJ).

\section{KARGER}




\section{Cellular Physiology Cell Physiol Biochem 2015;36:166-178 \begin{tabular}{l|l|l}
\hline DOI: 10.1159/000374061 & (C) 2015 S. Karger AG, Basel
\end{tabular} and Biochemistry Published online: April 30, $2015 \quad$ www.karger.com/cpb \\ Zhou et al.: SNP in EGFR 3'UTR Confers Risk for PH in COPD}

Western blot

Equal amount of cell lysates were loaded to SDS-polyacrylamide gel electrophoresis, and the separated proteins were next transferred onto a PVDF membrane, followed by blocking with TBST (10 mM Tris-Cl pH 8.0, $150 \mathrm{mM} \mathrm{NaCl}$, and $0.05 \%$ Tween 20 ) containing 5\% non-fat dry milk powder under room temperature for $1 \mathrm{hr}$. The PVDF membrane was then incubated with rabbit polyclonal antibody against EGFR (1:1000) (Santa Cruz, CA, USA) at $4^{\circ} \mathrm{C}$ overnight, followed by incubation with HRP-anti-rabbit secondary antibody at room temperature for $2 \mathrm{hr}$. Chemical fluorescence signal was detected using an ECL Kit (Pierce, Rockford, IL, USA) according to the manufacturer's protocol. The band of $\beta$-actin was used to normalize the result of target protein.

\section{Luciferase reporter plasmids and luciferase assays}

Full length of the EGFR 3'UTR was amplified from human genomic DNA sample using primer set 5'CCA CGG AGG ATA GTA TGA GCC CT-3'and 5'-AGA GTG GAA ATG AAT ATA G-3', and inserted into pcDNA3.0 (Invitrogen, Carlsbad, CA, USA). The sequence was confirmed by using direct Sanger sequencing. In addition, Quickchange XL site-directed mutagenesis kit was used to generate rs884225 774C or mutant with replacement of flanking sequence of rs884225, as described in Fig. 1A.

For luciferase assay, PASMCs were seeded onto 24 -well plates $\left(10^{5}\right.$ cells per well). PASMCs were transfected by Lipofectamin 2000 according to the manufacturer's instruction (Invitrogen, Carlsbad, CA, USA). In each well, 100 pmol of hsa-miR-214 mimics (Ambion, Austin, TX, USA) were cotransfected with 400ng EGFR 3'UTR luciferase reporter plasmids containing wild-type or mutant EGFR 3'UTR. Meanwhile, 100 pmol scramble sequences purchased from Ambion were used as negative control (NC) in every transfection experiment. As an internal control, all plasmids were contransfected with 8-ng pRL-SV40 containing the Renilla luciferase gene. Cells were collected $48 \mathrm{~h}$ after transfection, and cell lysates were followed by the manufacturer's suggestion. A Dual-Luciferase Reporter Assay System was used to measure the luciferase activity (Promega, Madison, WI, USA), which was normalized against the activity of the Renilla luciferase gene. Transfections were conducted in independent triplicate experiments.

\section{Statistical analysis}

The statistical analysis was performed by using the SPSS software (Chicago, IL, USA), and $P$ value of $<0.05$ was considered statistically significant. Comparison of selected demographic or clinicopathological variables between the cases and controls were evaluated using $\chi 2$ test or student t-test. Hardy-Weinberg equilibrium of the genotype distribution among the controls was tested by a goodness-of-fit $\chi 2$ test. Unconditional univariate and multivariate logistic regression analyses were conducted to calculate the crude and adjusted odds ratios (ORs) and their 95\% confidence intervals (CIs) for risk of PH. The luciferase reporter gene expression in different constructs was evaluated by one-way ANOVA tests.

\section{Results}

Characteristics of the participants

The demographic and clinicopathological characteristics of the subjects are shown in Table 1. The COPD patients with and without PH appeared to be sufficiently matched on age

Table 1. Demographic data and clinical characteristic of the participants recruited in this study

\begin{tabular}{llll}
\hline & $\begin{array}{l}\text { COPD PH(-) } \\
(\mathrm{n}=218)\end{array}$ & $\begin{array}{l}\text { COPD PH(+) } \\
(\mathrm{n}=110)\end{array}$ & P value \\
\hline Age (years) & $74.5 \pm 9.4$ & $75.6 \pm 9.8$ & 0.325 \\
Gender (F/M) & $45 / 173 ;$ & $21 / 89$ & 0.741 \\
Height $(\mathrm{cm})$ & $167.6 \pm 9.8$ & $165.7 \pm 9.2$ & 0.092 \\
Weight $(\mathrm{kg})$ & $60.5 \pm 8.2$ & $60.8 \pm 8.6$ & 0.758 \\
Smoking (pack*years) & $22.8 \pm 7.3$ & $36.6 \pm 8.8$ & $<0.01$ \\
FVC (\% of predicted value) & $62.6 \pm 7.3$ & $60.2 \pm 8.6$ & $<0.01$ \\
FEV $(\%$ of predicted value) & $58.8 \pm 7.7$ & $48.7 \pm 8.8$ & $<0.01$ \\
DLCO (\% of predicted value) & $96.6 \pm 10.4$ & $91.1 \pm 8.3$ & $<0.01$ \\
RV (\% of predicted value) & $126.9 \pm 21.3$ & $143.5 \pm 26.5$ & $<0.01$ \\
\hline
\end{tabular}




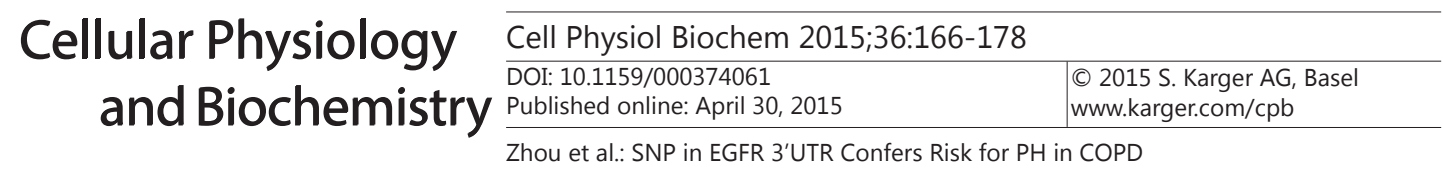

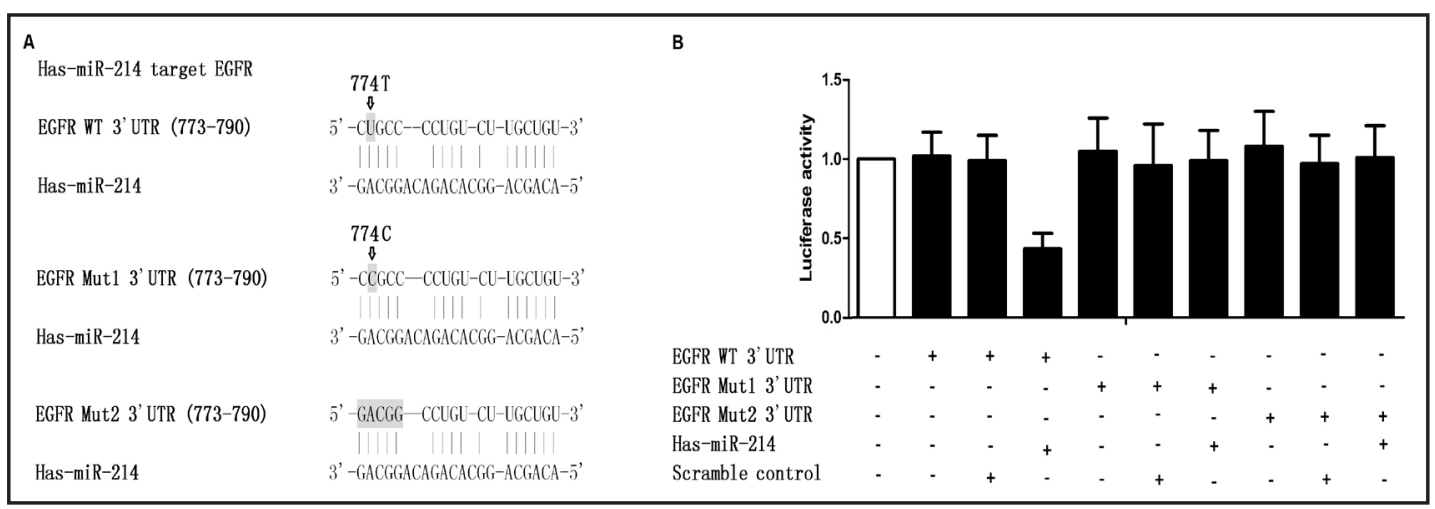

Fig. 1. A, Comparison of the sequences of EGFR 3'UTR $774 \mathrm{~T}, 774 \mathrm{C}$ and mutant with replacement of binding site against the sequence of miR-214; B, Only the luciferase acticity in the cells cotransfected with wild-type EGFR 3'UTR and miR-214 was significantly reduced compared with those transfected with wild-type EGFR 3'UTR and scramble control $(\mathrm{P}<0.01)$.

Table 2. Genotype frequencies of EGFR 3'UTR 774T $>$ C polymorphism (rs884225) among the cases and controls and their association with presen-

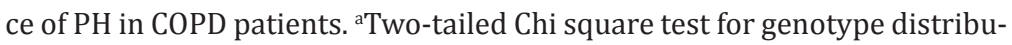
tion. ${ }^{b}$ Adjusted for age, gender, BMI and smoking index in logistic regression model

\begin{tabular}{|c|c|c|c|c|}
\hline & COPD PH(-) $(n=218)$ & COPD PH(+) $(n=110)$ & P value ${ }^{a}$ & Adjusted OR $(95 \% \mathrm{CI})$ \\
\hline & $\mathrm{N}(\%)$ & $\mathrm{N}(\%)$ & & \\
\hline \multicolumn{5}{|c|}{ Genotype } \\
\hline TT & $61(28.0 \%)$ & $25(22.7 \%)$ & 0.0282 & 1.00 (reference) \\
\hline $\mathrm{TC}$ & $108(49.5 \%)$ & $45(40.9 \%)$ & & $1.010(0.548-1.756)$ \\
\hline $\mathrm{CC}$ & 49 (22.5\%) & $40(36.4 \%)$ & & $1.956(1.058-3.649)$ \\
\hline \multicolumn{5}{|c|}{ Combined } \\
\hline $\mathrm{TT} / \mathrm{TC}$ & 169 (77.5\%) & $70(63.6 \%)$ & 0.0081 & 1.00 (reference) \\
\hline \multirow[t]{2}{*}{ CC } & 49 (22.5\%) & $40(36.4 \%)$ & & $1.965(1.185-3.158)$ \\
\hline & & & & $P$ value $=0.0095$ \\
\hline
\end{tabular}

$(P=0.325)$, sex $(P=0.741)$ and height $(P=0.092)$ and weight $(P=0.758)$. However, smoking index in COPD patients with PH was significantly higher than those without PH $(\mathrm{p}<0.01)$. Conversely, FEV1, FVC, DLCO and RV were significantly higher in COPD patients without PH than those without PH. Therefore, these variables were included in the multivariate logistic regression analysis to evaluate the potential effects on the association between EGFR $3^{\prime}$ UTR $774 \mathrm{~T}>\mathrm{C}$ polymorphism and the risk of development of $\mathrm{PH}$ in COPD patients.

Association analysis between EGFR $3^{\prime} U T R$ 774T $>C$ polymorphism and risk of $P H$ in COPD

Genotype frequency of EGFR 774T $>$ C polymorphism among the case and control subjects and their associations with PH risk in COPD are presented in Table 2. The frequencies of the TT, TC and CC genotypes were 28.0, 49.5 and $22.5 \%$, respectively, among the controls and $22.7,40.9$ and $36.4 \%$, respectively, among the cases ( $\mathrm{P}=0.0095)$. When we used the TT genotype as the reference, we noted that the CC genotype was associated with a statistically significantly increased risk of PH in COPD (adjusted OR $=1.956,95 \%$ CI $=1.058-3.649$ ). Also, a similar trend was observed in the CC genotype compared with the combined TT/TC genotypes $(1.965,1.185-3.158)$.

\section{Effect of the EGFR 3'UTR 774T>C on EGFR expression in PASMCs}

It has been previously shown that EGFR was a validated target of miR-214 in human bladder cancer cells [12]. Based on the computational analysis, the EGFR 774T $>C$ polymorphism was found to be located within a predicted binding site for hsa-miR-214 (Fig. 


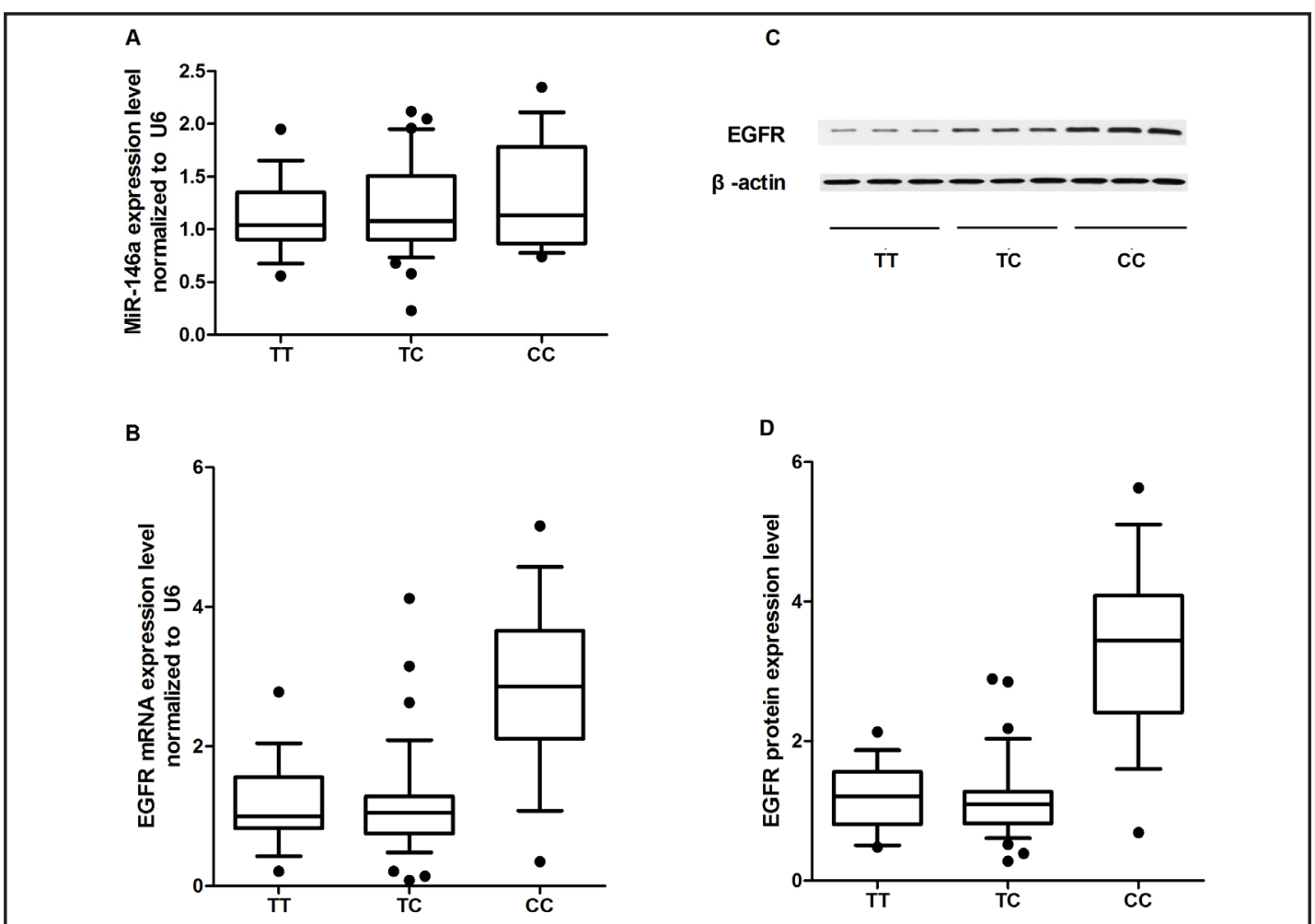

Fig. 2. lung tissues harvested from individuals with TT (18), TC(38) and CC(16), and miR-214 (A), EGFR mRNA (B) and protein (C) expression levels were examined by using real-time PCR and western blot. The target protein bands were densitometrically analyzed (D).

1). To test whether hsa-miR-214 targets EGFR 3'UTR in PASMCs, we constructed reporter vectors carrying wild-type or mutant EGFR 3'UTR, as described in Fig. 1A. Subsequently, we used them for transient transfection with the PASMCs together with miR-214 mimics or scramble controls. As shown in Fig. 1B, only the luciferase activity from the PASMCs cotransfected with wild-type EGFR 3'UTR and miR-214 mimics was significantly lower than the control $(p<0.01)$, and all other groups were comparable compared with the NC. Our data indicated that EGFR was a validated target of miR-214 in PASMCs, and 774T is the key nucleotide during interaction between miR-214 and EGFR 3'UTR, loss of which may completely abrogate the miRNA/mRNA interaction in PASMCs.

Determination of expression patterns of miR-214 and EGFR in lung tissues of different EGFR 3'UTR 774T/C genotypes

Lung tissues of three different genotypes (TT, n=18, TC, n=38, CC, n=16) were used to further explore the impacts of rs884225 polymorphism on the interaction between miR214 and EGFR 3'UTR. To characterize the role of rs884225 polymorphism on the miRNA/ mRNA interaction in PASMC which plays a central role in the development of $\mathrm{PH}$, we isolated and explant cultured the PASMCS collected from resected lung tissues, and quantified the expression of miR-214 and EGFR by using real-time PCR as well as western blot. As shown in Fig. 2, while the expression level of miR-214 were similarly distributed among each genotype group, the mRNA and protein expression level of EGFR in CC genotype group were significantly higher than TT and TC groups.

Exogenous upregulation or downregulation of miR-214 altered the expression of EGFR as well as the cell proliferation in PASMCs with TT genotype

The lung tissues of TT genotype were obtained from the patients who received surgical treatment, and the PASMCs were isolated, genotyped and explant cultured prior to the 
A
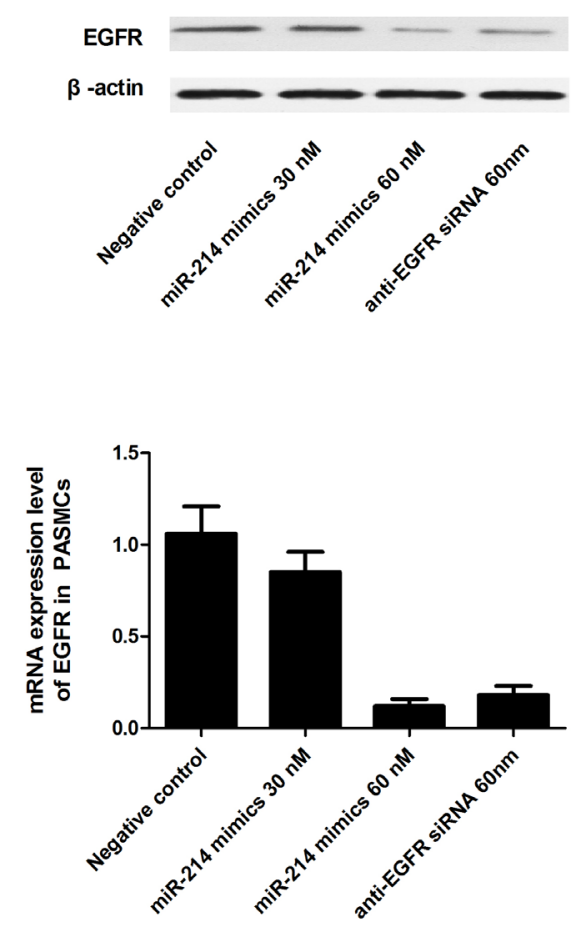
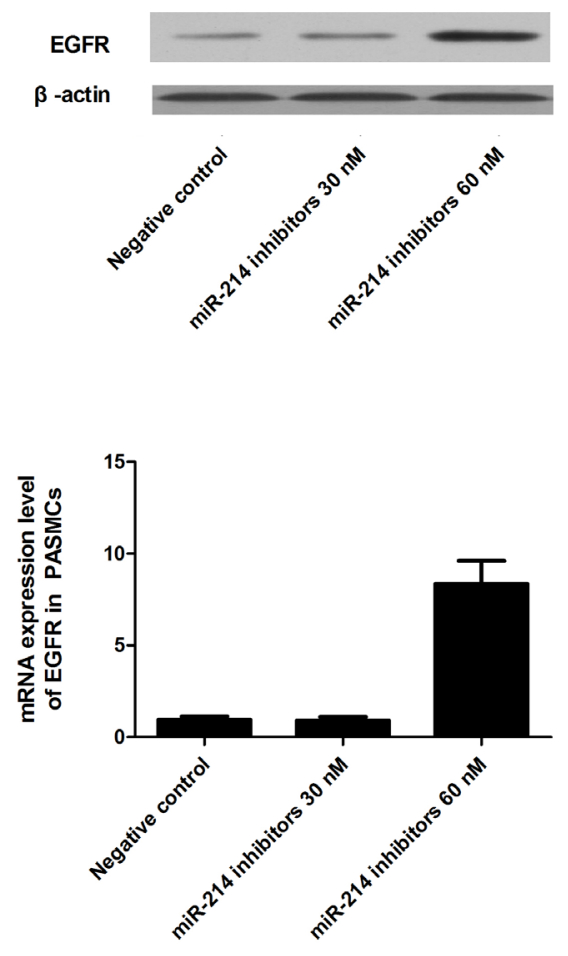

Fig. 3. PASMCs were harvested from the individual genotyped as EGFR 3'UTR 774TT, and transfected with control, miR-214 mimics and anti-EGFR siRNA (A) as well as miR-214 inhibitors; Protein (A upper panel) and mRNA (A lower panel) expression levels of EGFR were evaluated in PASMCS 48 hours after transfected with control, miR-214 mimics and anti-EGFR siRNA; Protein (B upper panel) and mRNA (B lower panel) expression levels of EGFR were evaluated in PASMCS 48 hours after transfected with control and miR-214 inhibitors.

functional analysis. To characterize the role of miR-214 in regulating EGFR and cellular behavior, miRNA mimics ( $30 \mathrm{nM}$ and $60 \mathrm{nM}$ ) together with anti-EGFR siRNA (60 $\mathrm{nM}$ ) were introduced into PASMCs, and as a result, the expression level of miR-214 was increased up to 10 and 30 times 48 hours after transfection (data not shown). As shown in Fig. 3A, transfection of miR-214 mimics significantly lowered the mRNA and protein expression level of EGFR in a concentration dependent manner, and the effect of anti-EGFR siRNA on the expression of EGFR was comparable with miR-214 of same concentration. Meanwhile, introduction of miR-214 inhibitors significantly reduced the concentration of miR-214 down to $10 \%$ in PASMCs 48 hours after transfection. As shown in Fig. 3B, transfection of miR-214 inhibitors significantly upregulated the mRNA and protein expression level of EGFR. In line with this, upregulation or downregulation of miR-214 significantly altered the proliferation of PASMCs of TT genotype in the opposite direction by inhibiting or introducing apoptosis, respectively (Fig. 4).

Exogenous upregulation or downregulation of miR-214 did not modify the expression of EGFR or the cell proliferation in PASMCs genotyped as CC

To investigate the effect of rs884225 polymorphism on miRNA/mRNA interaction, we repeated the quantification of EGFR expression, MTT assay, apoptosis analysis in PASMCs with CC genotype transfected with miR-214 mimics, inhibitors, or anti-EGFR siRNA. As shown in Fig. 5, exogenous upregulation or downregulation of miR-214 did not alter either mRNA or protein expression level of EGFR. Consistently, such change in miR-214 altered neither the 
Fig. 4. The proliferation of PASMCs harvested from the individual genotyped as EGFR 3'UTR 774TT were evaluated by using BrdU incorporation assay (all $\mathrm{P}<0.05$ compared with scramble control) (A), and the apoptosis status of the cells transfected with scramble control (B), miR-214 mimics $30 \mathrm{nM}$ (C), miR-214 mimics 60 nM (D), anti-EGFR siRNA $60 \mathrm{nM}$ (E), miR-214 inhibitors $30 \mathrm{nM}$ (F) and $60 \mathrm{nM}(\mathrm{G})$ were evaluated by using flowcytometry (left lower quadrant refers to the live cells, and all others are apoptotic cells).
A

B
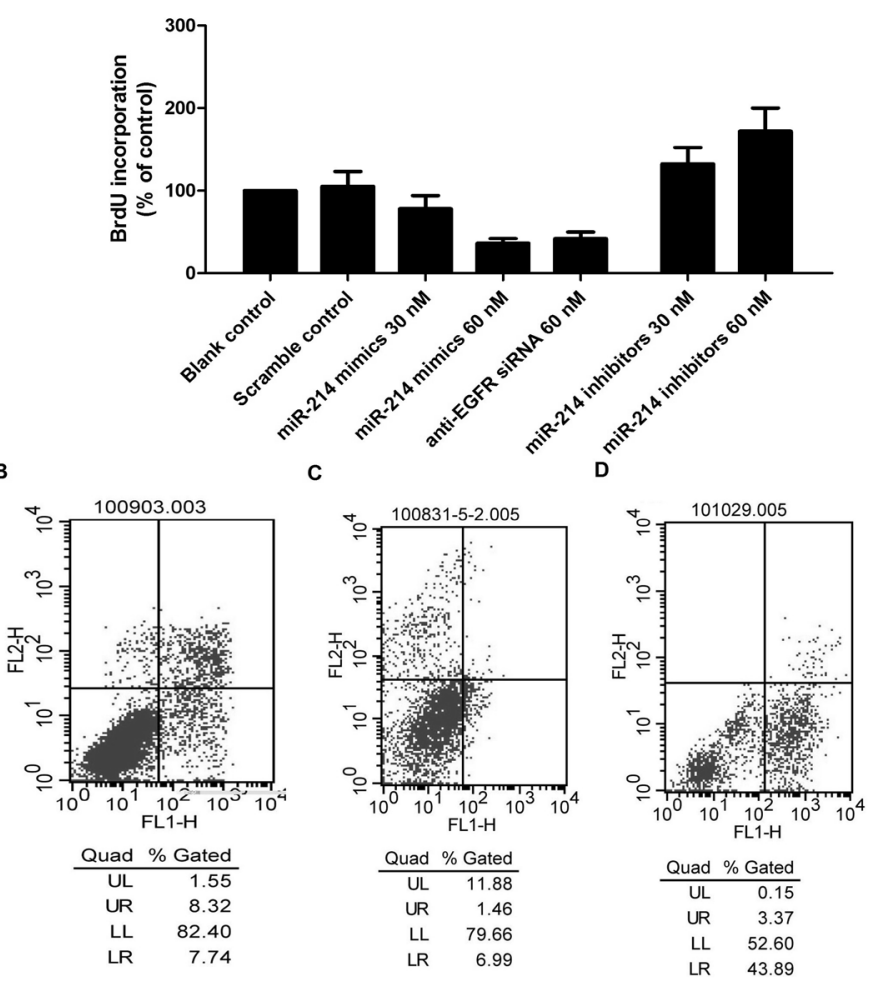

E

F

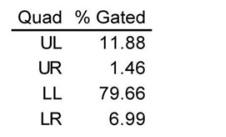

G
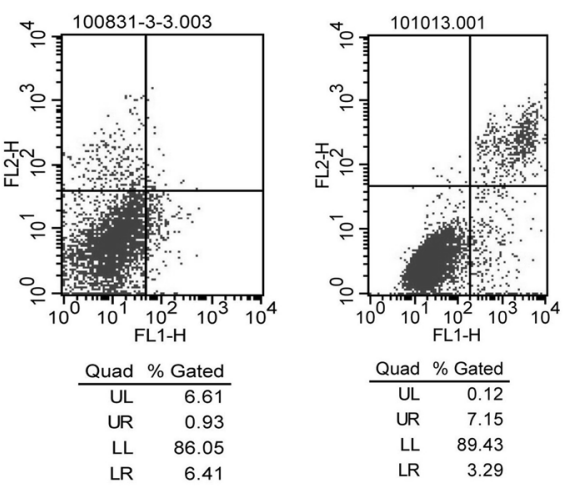

proliferation nor apoptosis status in PASMCs genotyped as CC (Fig. 6), whereas the effects of anti-EGFR siRNA on the expression of EGFR, cell proliferative ability, or apoptosis were similar between the PASMCs of TT or CC genotypes (Fig. 5 and 6).

\section{Discussion}

$\mathrm{PH}$ has been identified in approximately one third of patients with COPD [25], up to $91 \%$ of patients with COPD have experienced exercise-induced $\mathrm{PH}$ [26], and these patients tend to have more moderate airway obstruction, significant hypoxia, less hypercapnia, and significantly impaired survival [27]. According to the World Health Organization (WHO) classification (WHO group III) [28], $\mathrm{PH}$ associated with lung diseases that generate a hypoxic environment, such as COPD, is regarded as a separate entity. It has been proposed that hypoxia, as a result of COPD, is the major cause of artery remodeling, the structure basis of $\mathrm{PH}$, with some other factors such as polycythemia and hypercapnia as minor causes of the disease [29, 30], as well as the dysregulation of certain genes [31-33]. In this study, 328 


\begin{tabular}{|c|c|c|}
\hline \multirow{2}{*}{$\begin{array}{l}\text { Cellular Physiology } \\
\text { and Biochemistry }\end{array}$} & Cell Physiol Biochem 2015;36:166-178 & \\
\hline & $\begin{array}{l}\text { Dol: 10.1159/0000374061 } \\
\text { Published online: }\end{array}$ & $\begin{array}{l}\text { (0 2015. Sarger AG, Basel } \\
\text { www.kargercom/cob }\end{array}$ \\
\hline
\end{tabular}

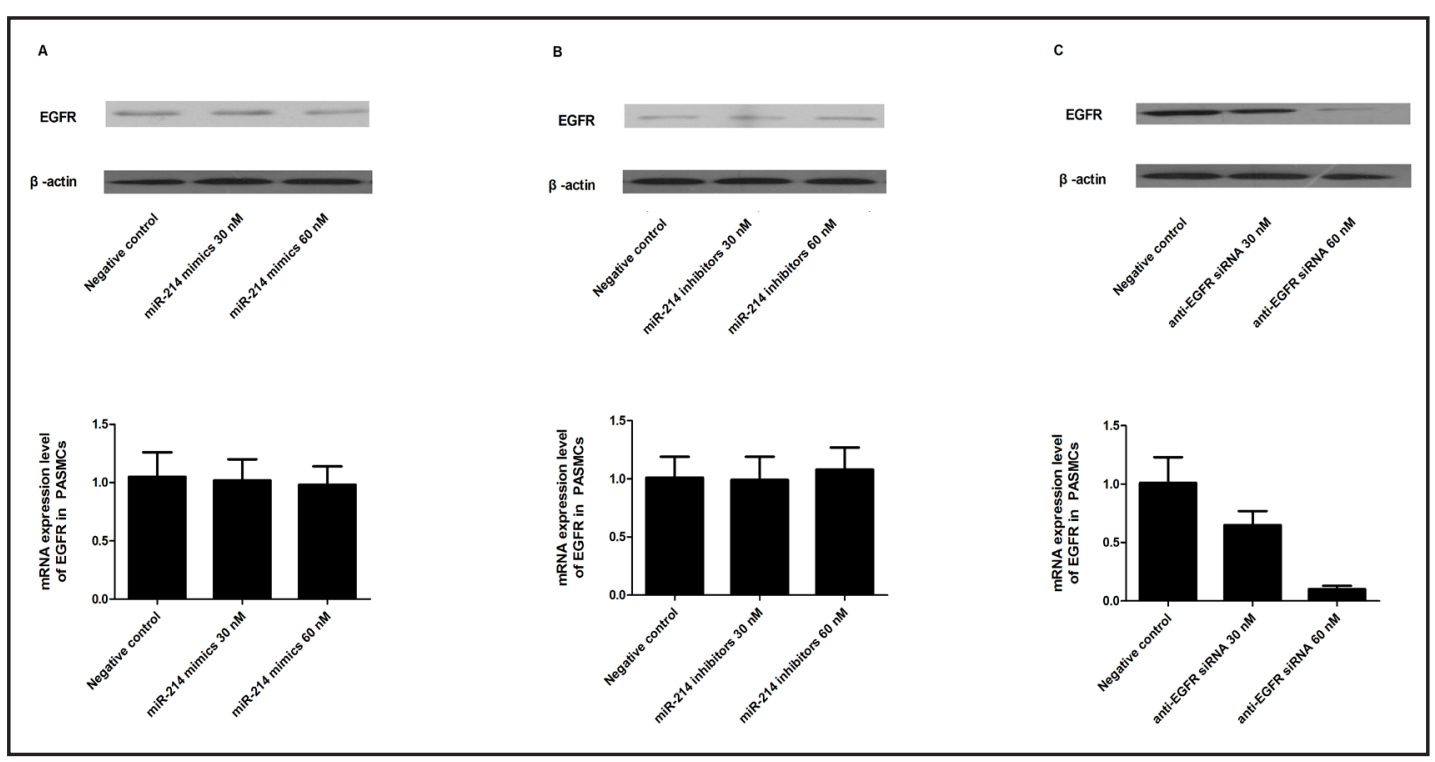

Fig. 5. PASMCs were harvested from the individual genotyped as EGFR 3'UTR 774 CC, and transfected with miR-214 mimics (A), miR-214 inhibitors (B) and and anti-EGFR siRNA (C); Protein (A upper panel) and mRNA (A lower panel) expression levels of EGFR were evaluated in PASMCS 48 hours after transfected with control and miR-214 mimics; Protein (B upper panel) and mRNA (B lower panel) expression levels of EGFR were evaluated in PASMCS 48 hours after transfected with control and miR-214 inhibitors; Protein (C upper panel) and mRNA (C lower panel) expression levels of EGFR were evaluated in PASMCS 48 hours after transfected with control and anti-EGFR siRNA.

COPD patients with PH $(n=110)$ and without PH $(n=218)$ were recruited, and we found that compared with TT and TC genotypes, patients with CC genotype had significantly higher risk for OA $(\mathrm{OR}=1.975, \mathrm{p}=0.0095]$. Meanwhile, the PASMCs were isolated from 72 COPD patients, with which miR-214 and EGFR expression levels were determined, and we found that miR-214 level was comparable between each genotype group, the concentration of EGFR in CC genotype group was significantly higher than in TT or TC genotype group.

MicroRNA plays an important role in the control of cellular activities by modulating transcription and translation of target mRNAs. Over 1,000 miRNAs have been reported to be encoded within the human genome and these miRNAs are estimated to target one third of genes. The discovery of miRNAs has introduced a new level of complexity for every biological process when exploring regulatory network [34], and their dysregulation causes various medical disorders including malignancy [35], inflammation [36] and heart disease [37]. Several miRNAs have been implicated in lung disease such as COPD, asthma, idiopathic pulmonary fibrosis (IPF), and cystic fibrosis [38, 39]. Collectively, these studies showed that miRNAs are expressed in the lung and are involved in the pathogenesis of a wide spectrum of lung diseases. Simultaneously, miRNAs have been shown to be involved in the development of PH. Courboulin et al. [40] found that miR-204 was downregulated in PASMCs from the patients with $\mathrm{PH}$ as well as the PASMCs from rats with monocrotaline-induced $\mathrm{PH}$, and they showed that reconstitution of miR- 204 attenuated monocrotaline-induced PAH in rats. Caruso et al. [40] performed miRNA profiling and found that a number of miRNAs demonstrated significantly altered expressions in the lungs of rats that were exposed to hypoxia or were given monocrotaline. These data suggested that miRNAs participate in the pathogenesis of PAH in both patients and rodent models. In this study, we validated EGFR as a target of miR-214 in PASMCs, and rs884225 polymorphism located at microRNA (miRNA) binding sites may interfere with the miRNA/mRNA interaction with luciferase reporter system. Furthermore, we confirmed the results of luciferase assay by the observation that exogenous overexpression of miR-214 significantly downregulated the expression of EGFR in the PASMCs genotyped as TT, but not in CC group.

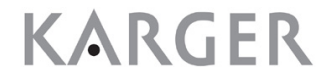


Fig. 6. The proliferation PASMCs were harvested from the individual genotyped as EGFR 3'UTR 774CC were evaluated (A), and the apoptosis status of the cells transfected with scramble control (B), miR-214 mimics 30 nM (C), miR-214 mimics $60 \mathrm{nM}$ (D), miR214 inhibitors $30 \mathrm{nM}$ (E), miR-214 inhibitors 60 nM (F), anti-EGFR siRNA $30 \mathrm{nM}(\mathrm{G})$ and $60 \mathrm{nM}(\mathrm{H})$ were evaluated by using flowcytometry (left lower quadrant refers to the live cells, and all others are apoptotic cells).
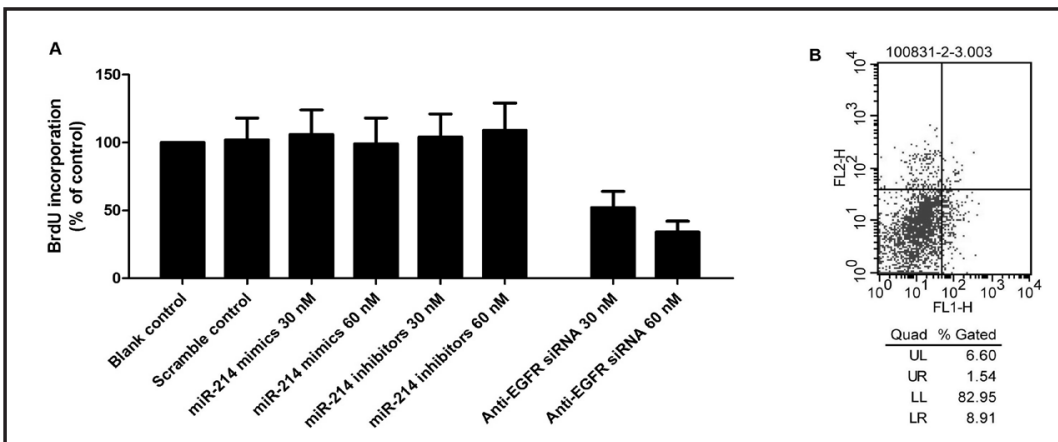

c

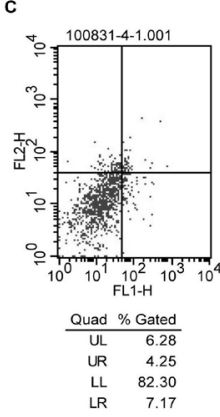

D
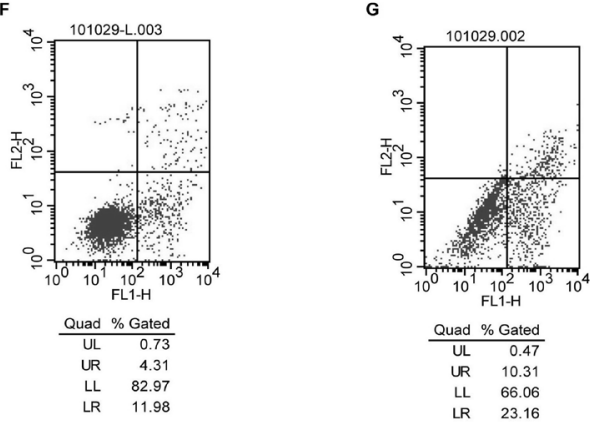

$\mathrm{E}$

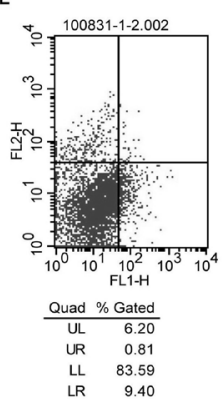

H

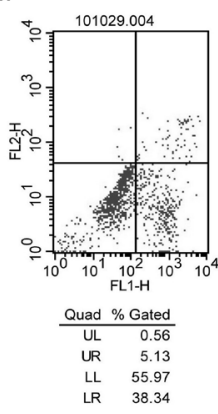

MiR-214 gene is mapped to q24.3 of chromosome 1. It has been implicated to be differentially expressed in various tumors [41-43]. Accumulative evidence demonstrated that miR-214 may play a conflicting role in the control of cell proliferation, as evidenced by its function either as onco-gene or tumor suppressor gene in different tumors. In this study, we found that introduction of miR-214 could suppress the growth of PASMCs via targeting EGFR and inhibiting apoptosis, and consistently, inhibition of miR-214 could significantly upregulate EGFR and thereby accelerating the proliferation of PASMCs genotyped as TT or TC. Whereas such results were not observed in the PASMCs with CC genotype, i.e. alternation of miR-214 showed minimal effect on the proliferation of the cells or the apoptosis status in the cells with homozygous allele.

EGFR signaling pathway plays an important role in regulating many cellular biological behaviors, including cell proliferation, survival and apoptosis [44, 45], which has been proved to be mainly mediated by activation of two downstream pathways, one is phosphatidylinositol-3 kinase (PI3K)-AKT pathway and the other is mitogen-activated protein kinase (MAPK) pathway [46]. It has been shown that over-expression of EGFR contributed to the development of $\mathrm{PH}$ by abnormally accelerating the proliferation of PASMCs, and administration of its inhibitor (PKI166), working via competitive inhibition of the binding of ATP to the TK domain of the receptor, resulted in improved long-term survival with associated reversal of progressive vascular remodeling [13]. Treatment with antibody targeting the EGFR pathway inhibited smooth muscle cell proliferation in balloon-injured rat 


\begin{tabular}{|c|c|c|}
\hline Cellular Physiology & Cell Physiol Biochem 2015;36:166-178 & \\
\hline and Biochemistry & $\begin{array}{l}\text { DOI: 10.1159/000374061 } \\
\text { Published online: April 30, } 2015\end{array}$ & $\begin{array}{l}\text { O } 2015 \text { S. Karger AG, Basel } \\
\text { www.karger.com/cpb }\end{array}$ \\
\hline
\end{tabular}

carotid arteries [47], and caused significant regression of human tumor xenografts in mice [48].

To date, many studies proposed that SNPs located in the 3'UTR of miRNA target genes may affect gene expression and thus be associated with individual disease development. Based on the bioinformatics analysis, rs884225e polymorphism lies within a predicted binding site for hsa-miR-214. Chu et al. showed that EGFR 774CC genotype was associated with a significantly increased risk of bladder cancer [12], while no significant association was identified between the polymorphism and bladder cancer in a Korean population. In this study, the results showed that the EGFR 774CC genotype was associated with a significantly increased susceptibility to PH in COPD patients compared with 774TT/TC genotype. Additionally, luciferase reporter gene assay confirmed that EGFR 3'UTR $774 \mathrm{~T}$ to C substitution could interfere with the interaction between EGFR 3'UTR and miR-214, which was consistent with the association results to increase the risk of PH in COPD.

Some limitations should be mentioned in the present study. First, our study is based on a hospital-based cohort, which makes selection bias of subjects an unavoidable issue; Secondly, the relative small sample size of the cohort limits the statistical power of the study, and refrains us from further stratification analysis; Thus, the data should be interpreted with caution. Even though we performed functional analysis to support the association study results, further study with larger or different ethnic population is warranted to reproduce the results of the present study.

Despite these limitations, this observational study brings us forward in understanding the mechanism underlying the development of $\mathrm{PH}$ in patients with COPD. This study provides further evidence that EGFR 3'UTR 774T $>$ C polymorphism interfered with the miRNA/mRNA interaction, and released the physiological inhibition of EGFR by miR-214 in PASMCs with minor allele. Such progression in understanding of the pathogenesis of PH in COPD shed a light on the prevention and treatment of $\mathrm{PH}$, especially in the patient population with COPD.

\section{Acknowledgements}

This research was supported by the fund from the Natural Science Foundation of China (No.81300041, No.81100038), the fund from the Natural Science Foundation of the Anhui Higher Education Institutions of China (No.KJ2012Z184), the fund for the academic backbone of the excellent young and middle-age people of Anhui medical university (2013), the fund from the first affiliated hospital of Anhui medical university for reserve talents (2014).

\section{Disclosure Statement}

The authors claim no conflict of interest

\section{References}

1 Vestbo J, Hurd SS, Rodriguez-Roisin R: The 2011 revision of the global strategy for the diagnosis, management and prevention of COPD (GOLD)--why and what? Clin Respir J 2012;6:208-214.

2 Agusti AG, Noguera A, Sauleda J, Sala E, Pons J, Busquets X: Systemic effects of chronic obstructive pulmonary disease. Eur Respir J 2003;21:347-360.

3 Galiè N, Torbicki A, Barst R, Dartevelle P, Haworth S, Higenbottam T, Olschewski H, Peacock A, Pietra G, Rubin LJ, Simonneau G, Priori SG, Garcia MA, Blanc JJ, Budaj A, Cowie M, Dean V, Deckers J, Burgos EF, Lekakis J, Lindahl B, Mazzotta G, McGregor K, Morais J, Oto A, Smiseth OA, Barbera JA, Gibbs S, Hoeper M, Humbert M, Naeije R, Pepke-Zaba J; Task Force: Guidelines on diagnosis and treatment of pulmonary arterial hypertension. The Task Force on Diagnosis and Treatment of Pulmonary Arterial Hypertension of the European Society of Cardiology. Eur Heart J 2004;25:2243-2278. 


\section{Cellular Physiology Cell Physiol Biochem 2015;36:166-178 \begin{tabular}{l|l|l} 
DOI: 10.1159/000374061 & (C) 2015 S. Karger AG, Basel
\end{tabular} and Biochemistry Published online: April 30, $2015 \quad$ www.karger.com/cpb \\ Zhou et al.: SNP in EGFR 3'UTR Confers Risk for PH in COPD}

4 Wells A: EGF receptor. Int J Biochem Cell Biol 1999;31:637-643.

5 Jorissen RN, Walker F, Pouliot N, Garrett TP, Ward CW, Burgess AW: Epidermal growth factor receptor: mechanisms of activation and signalling. Exp Cell Res 2003;284:31-53.

6 Lin SY, Makino K, Xia W, Matin A, Wen Y, Kwong KY, Bourguignon L, Hung MC: Nuclear localization of EGF receptor and its potential new role as a transcription factor. Nat Cell Biol 2001;3:802-808.

$7 \quad$ Neal DE, Sharples L, Smith K, Fennelly J, Hall RR, Harris AL: The epidermal growth factor receptor and the prognosis of bladder cancer. Cancer 1990;65:1619-1625.

8 Wankel B, Schulze H: [Comprehensive review: veterinary medicine and wild animal research]. Dtsch Tierarztl Wochenschr 1976;83:383-386 contd.

9 Arteaga CL: The epidermal growth factor receptor: from mutant oncogene in nonhuman cancers to therapeutic target in human neoplasia. J Clin Oncol 2001;19:32S-40S.

10 Merklinger SL, Jones PL, Martinez EC, Rabinovitch M: Epidermal growth factor receptor blockade mediates smooth muscle cell apoptosis and improves survival in rats with pulmonary hypertension. Circulation 2005;112:423-431.

11 Dahal BK, Cornitescu T, Tretyn A, Pullamsetti SS, Kosanovic D, Dumitrascu R, Ghofrani HA, Weissmann N, Voswinckel R, Banat GA, Seeger W, Grimminger F, Schermuly RT: Role of epidermal growth factor inhibition in experimental pulmonary hypertension. Am J Respir Crit Care Med 2010;181:158-167.

12 Chu H, Wang M, Jin H, Lv Q, Wu D, Tong N, Ma L, Shi D, Zhong D, Fu G, Yuan L, Qin C, Yin C, Zhang Z: EGFR 3'UTR 774T>C polymorphism contributes to bladder cancer risk. Mutagenesis 2013;28:49-55.

13 Bartel DP: MicroRNAs: genomics, biogenesis, mechanism, and function. Cell 2004;116:281-297.

14 Carthew RW: Gene regulation by microRNAs. Curr Opin Genet Dev 2006;16:203-208.

15 Pillai RS: MicroRNA function: multiple mechanisms for a tiny RNA? RNA 2005;11:1753-1761.

16 Garzon R, Fabbri M, Cimmino A, Calin GA, Croce CM: MicroRNA expression and function in cancer. Trends Mol Med 2006;12:580-587.

17 Chen L, Li YS, Cui J, Ning JN, Wang GS, Qian GS, Lu KZ, Yi B: MiR-206 controls the phenotypic modulation of pulmonary arterial smooth muscle cells induced by serum from rats with hepatopulmonary syndrome by regulating the target gene, annexin A2. Cell Physiol Biochem 2014;34:1768-1779.

18 Wang R, Li M, Zhou SJ, Zeng DX, Xu X, Xu R, Sun GY: Effect of a single nucleotide polymorphism in miR-146a on COX-2 protein expression and lung function in smokers with chronic obstructive pulmonary disease. Int J Chron Obstruct Pulmon Dis 2015;10:463-473.

19 Saunders MA, Liang H, Li WH: Human polymorphism at microRNAs and microRNA target sites. Proc Natl Acad Sci U S A 2007;104:3300-3305.

20 Clop A1, Marcq F, Takeda H, Pirottin D, Tordoir X, Bibé B, Bouix J, Caiment F, Elsen JM, Eychenne F, Larzul C, Laville E, Meish F, Milenkovic D, Tobin J, Charlier C, Georges M: A mutation creating a potential illegitimate microRNA target site in the myostatin gene affects muscularity in sheep. Nat Genet 2006;38:813-818.

21 Georges M, Coppieters W, Charlier C: Polymorphic miRNA-mediated gene regulation: contribution to phenotypic variation and disease. Curr Opin Genet Dev 2007;17:166-176.

22 Sethupathy P, Collins FS: MicroRNA target site polymorphisms and human disease. Trends Genet 2008;24:489-497.

23 Chen K, Song F, Calin GA, Wei Q, Hao X, Zhang W: Polymorphisms in microRNA targets: a gold mine for molecular epidemiology. Carcinogenesis 2008;29:1306-1311.

24 Blitzblau RC, Weidhaas JB: MicroRNA binding-site polymorphisms as potential biomarkers of cancer risk. Mol Diagn Ther 2010;14:335-342.

25 Weitzenblum E: Chronic cor pulmonale. Heart 2003;89:225-230.

26 Scharf SM, Iqbal M, Keller C, Criner G, Lee S, Fessler HE: National Emphysema Treatment Trial (NETT) Group: Hemodynamic characterization of patients with severe emphysema. Am J Respir Crit Care Med 2002;166:314-322.

27 Weitzenblum E, Chaouat A: Severe pulmonary hypertension in COPD: is it a distinct disease? Chest 2005;127:1480-1482.

28 Simonneau G, Galiè N, Rubin LJ, Langleben D, Seeger W, Domenighetti G, Gibbs S, Lebrec D, Speich R, Beghetti M, Rich S, Fishman A: Clinical classification of pulmonary hypertension. J Am Coll Cardiol 2004;43:5S-12S.

29 Ooi H, Cadogan E, Sweeney M, Howell K, O’Regan RG McLoughlin P: Chronic hypercapnia inhibits hypoxic pulmonary vascular remodeling. Am J Physiol Heart Circ Physiol 2000;278:H331-338. 


\section{Cellular Physiology Cell Physiol Biochem 2015;36:166-178 \begin{tabular}{l|l|l}
\hline DOI: 10.1159/000374061 & (C) 2015 S. Karger AG, Basel
\end{tabular} www.karger.com/cpb \\ Zhou et al.: SNP in EGFR 3'UTR Confers Risk for PH in COPD}

30 Weissmann N, Manz D, Buchspies D, Keller S, Mehling T, Voswinckel R, Quanz K, Ghofrani HA, Schermuly RT, Fink L, Seeger W, Gassmann M, Grimminger F: Congenital erythropoietin over-expression causes "anti-pulmonary hypertensive" structural and functional changes in mice, both in normoxia and hypoxia. Thromb Haemost 2005; 94:630-638.

31 Wang R, Xu YJ, Liu XS, Zeng DX, Xiang M: Knockdown of connective tissue growth factor by plasmid-based short hairpin RNA prevented pulmonary vascular remodeling in cigarette smoke-exposed rats. Arch Biochem Biophys 2011;508:93-100.

32 Wang R, Xu YJ, Liu XS, Zeng DX, Xiang M: CCN2 promotes cigarette smoke-induced proliferation of rat pulmonary artery smooth muscle cells through upregulating cyclin D1 expression. J Cell Biochem 2012;113:349-359.

33 Wang R, Zhou SJ, Zeng DX, Xu R, Fei LM, Zhu QQ, Zhang Y, Sun GY: Plasmid-based short hairpin RNA against connective tissue growth factor attenuated monocrotaline-induced pulmonary vascular remodeling in rats. Gene Ther 2014;21:931-937.

34 Chen XM, Splinter PL, O'Hara SP, LaRusso NF: A cellular micro-RNA, let-7i, regulates Toll-like receptor 4 expression and contributes to cholangiocyte immune responses against Cryptosporidium parvum infection. J Biol Chem 2007;282:28929-28938.

35 Yanaihara N, Caplen N, Bowman E, Seike M, Kumamoto K, Yi M, Stephens RM, Okamoto A, Yokota J, Tanaka T, Calin GA, Liu CG, Croce CM, Harris CC: Unique microRNA molecular profiles in lung cancer diagnosis and prognosis. Cancer Cell 2006;9:189-198.

36 O'Connell RM, Taganov KD, Boldin MP, Cheng G, Baltimore D: MicroRNA-155 is induced during the macrophage inflammatory response. Proc Natl Acad Sci U S A 2007;104:1604-1609.

37 Mann DL: MicroRNAs and the failing heart. N Engl J Med 2007;356:2644-2645.

38 Oglesby IK, McElvaney NG, Greene CM: MicroRNAs in inflammatory lung disease--master regulators or target practice? Respir Res 2010;11:148.

39 Jiang X: The emerging role of microRNAs in asthma. Mol Cell Biochem 2011;353:35-40,.

40 Courboulin A, Paulin R, Giguère NJ, Saksouk N, Perreault T, Meloche J, Paquet ER, Biardel S, Provencher S, Côté J, Simard MJ, Bonnet S: Role for miR-204 in human pulmonary arterial hypertension. J Exp Med 2011;208:535-548.

41 Yanaihara N1, Caplen N, Bowman E, Seike M, Kumamoto K, Yi M, Stephens RM, Okamoto A, Yokota J, Tanaka T, Calin GA, Liu CG, Croce CM, Harris CC: Unique microRNA molecular profiles in lung cancer diagnosis and prognosis. Cancer Cell 2006;9:189-198.

42 Magrelli A1, Azzalin G, Salvatore M, Viganotti M, Tosto F, Colombo T, Devito R, Di Masi A, Antoccia A, Lorenzetti S, Maranghi F, Mantovani A, Tanzarella C, Macino G, Taruscio D: Altered microRNA Expression Patterns in Hepatoblastoma Patients. Transl Oncol 2009;2:157-163.

43 Yang Z1, Chen S, Luan X, Li Y, Liu M, Li X, Liu T, Tang H: MicroRNA-214 is aberrantly expressed in cervical cancers and inhibits the growth of HeLa cells. IUBMB Life 2009;61:1075-1082.

44 Salomon DS, Brandt R, Ciardiello F, Normanno N: Epidermal growth factor-related peptides and their receptors in human malignancies. Crit Rev Oncol Hematol 1995;19:183-232.

45 Hanahan D, Weinberg RA: The hallmarks of cancer. Cell 2000;100:57-70.

46 Mendelsohn J, Baselga J: The EGF receptor family as targets for cancer therapy. Oncogene 2000;19:65506565.

47 Chan AK, Kalmes A, Hawkins S, Daum G, Clowes AW: Blockade of the epidermal growth factor receptor decreases intimal hyperplasia in balloon-injured rat carotid artery. J Vasc Surg 2003;37:644-649.

48 Goldstein NI, Prewett M, Zuklys K, Rockwell P, Mendelsohn J: Biological efficacy of a chimeric antibody to the epidermal growth factor receptor in a human tumor xenograft model. Clin Cancer Res 1995;1:13111318. 